\title{
Interaction between Mitochondrial Reactive Oxygen Species, Heme Oxygenase, and Nitric Oxide Synthase Stimulates Phagocytosis in Macrophages
}

\author{
Andrea Müllebner ${ }^{1,2}$, Gabriel G. Dorighello ${ }^{3}$, Andrey V. Kozlov² and J. Catharina \\ Duvigneau ${ }^{1 *}$
}

'Institute for Medical Biochemistry, University of Veterinary Medicine Vienna, Vienna, Austria, ${ }^{2}$ Ludwig Boltzmann Institute for Experimental and Clinical Traumatology, Vienna, Austria, ${ }^{3}$ Department of Structural and Functional Biology, Biology Institute, University of Campinas, Campinas, Brazil

\section{OPEN ACCESS}

Edited by:

Mikhail Kirov,

Northern State Medical

University, Russia

Reviewed by:

Lars Jakob Bjertnæs,

University of Tromsø, Norway

Evgeny Suborov

North-Western State Medical

University named after I.I.

Mechnikov, Russia

*Correspondence:

J. Catharina Duvigneau

catharina.duvigneau@

vetmeduni.ac.at

Specialty section:

This article was submitted

to Intensive Care Medicine

and Anesthesiology,

a section of the journal

Frontiers in Medicine

Received: 30 September 2017

Accepted: 19 December 2017

Published: 22 January 2018

Citation:

Müllebner A, Dorighello GG, Kozlov AV and Duvigneau JC (2018)

Interaction between Mitochondrial Reactive Oxygen Species, Heme

Oxygenase, and Nitric Oxide

Synthase Stimulates Phagocytosis in Macrophages.

Front. Med. 4:252

doi: 10.3389/fmed.2017.00252
Background: Macrophages are cells of the innate immune system that populate every organ. They are required not only for defense against invading pathogens and tissue repair but also for maintenance of tissue homeostasis and iron homeostasis.

Aim: The aim of this study is to understand whether heme oxygenase $(\mathrm{HO})$ and nitric oxide synthase (NOS) contribute to the regulation of nicotinamide adenine dinucleotide phosphate oxidase (NOX) activity and phagocytosis, two key components of macrophage function.

Methods: This study was carried out using resting J774A.1 macrophages treated with hemin or vehicle. Activity of NOS, HO, or NOX was inhibited using specific inhibitors. Reactive oxygen species (ROS) formation was determined by Amplex ${ }^{\circledR}$ red assay, and phagocytosis was measured using fluorescein isothiocyanate-labeled bacteria. In addition, we analyzed the fate of the intracellular heme by using electron spin resonance.

Results: We show that both enzymes NOS and $\mathrm{HO}$ are essential for phagocytic activity of macrophages. NOS does not directly affect phagocytosis, but stimulates NOX activity via nitric oxide-triggered ROS production of mitochondria. Treatment of macrophages with hemin results in intracellular accumulation of ferrous heme and an inhibition of phagocytosis. In contrast to NOS, HO products, including carbon monoxide, neither clearly affect NOX activity nor clearly affect phagocytosis, but phagocytosis is accelerated by $\mathrm{HO}$-mediated degradation of heme.

Conclusion: Both enzymes contribute to the bactericidal activity of macrophages independently, by controlling different pathways.

Keywords: macrophage, phagocytosis, heme oxygenase, nitric oxide synthase, reactive oxygen species, ROS, mitochondria

\section{INTRODUCTION}

Macrophages are cells of the innate immune system that can be found in all tissues. They are required for maintenance of tissue homeostasis, defense against invading pathogens, tissue repair, and red blood cell recycling. Macrophages maintain homeostasis by receptor-mediated recognition and phagocytic uptake of pathogenic or microbial material and damaged or apoptotic host cells. 
Degradation of the material taken up by phagocytosis is achieved via proteolytic enzymes and facilitated by the so-called oxidative burst. This involves the formation of reactive oxygen species (ROS) and nitric oxide (NO). Nicotinamide adenine dinucleotide phosphate (NADPH) oxidase (NOX) residing in the phagosomal membrane reduces oxygen $\left(\mathrm{O}_{2}\right)$ to superoxide anion $\left(\mathrm{O}_{2}^{-}\right)$. This leads to the formation of hydrogen peroxide $\left(\mathrm{H}_{2} \mathrm{O}_{2}\right)$ and the subsequent generation of highly reactive hydroxyl radicals via the Fenton reaction or the synthesis of hypochlorite by myeloperoxidase. In addition, the reaction of ROS with NO yields peroxynitrite, which together with hypochlorite is very effective antimicrobial agent (1). Altogether these reactive species are termed as reactive oxygen and nitrogen species.

Also mitochondrial ROS (mtROS) plays an important role in various innate immune signaling pathways (2). They activate NOX (3-5), the NLRP3 inflammasome (6), and were shown to drive synthesis of inflammatory cytokines (7). Furthermore, mtROS are believed to increase the phagocytic activity of macrophages (8).

It is known that generation of mtROS is regulated by diatomic gaseous messengers such as $\mathrm{NO}(9)$ and carbon monoxide (CO) (10). NO is formed from arginine by nitric oxide synthases (NOSs) and is a ubiquitous signaling messenger involved in multiple pathophysiologic reactions (11). NO acts as a reversible inhibitor of mitochondrial respiration by competing with $\mathrm{O}_{2}$ for binding to the heme moiety of cytochrome $c$ oxidase (COX). NO also reacts with iron sulfur clusters in complex I and II of the mitochondrial electron transport chain (mETC) (12). However, this effect is more likely assigned to the formation of peroxynitrite. Peroxynitrite inhibits the complexes of the mETC irreversibly (13). Both reversible and irreversible inhibitions of the mETC were shown to enhance mtROS formation in different model systems (9).

$\mathrm{CO}$ is a product of heme degradation by heme oxygenase (HO). $\mathrm{CO}$ targets cellular heme-containing proteins, including soluble guanylate cyclase $(14,15)$, $\operatorname{NOS}(16,17)$, and NOX (18). Similar to $\mathrm{NO}, \mathrm{CO}$ also competes with $\mathrm{O}_{2}$ for binding to COX. Higher levels of $\mathrm{CO}$ were shown to inhibit $\mathrm{COX}$ and to raise the production of mtROS, without decreasing mitochondrial potential (19).

Nitric oxide synthase and HO play an opposing role for the regulation of macrophage function, despite the similarity of the biological action of NO and CO. Macrophages with elevated NOS activity are considered to display a pro-inflammatory phenotype, associated with the generation of NO and peroxynitrite (20). In contrast, upregulated $\mathrm{HO}$ is associated with a tissue-protective phenotype $(21,22)$ and suppressed pro-inflammatory cytokine

\footnotetext{
Abbreviations: CO, carbon monoxide; COX, cytochrome oxidase; CrMP, chromium mesoporphyrin; DEA/NO, diethylamine NONOate; DETA/NO, diethylenetriamine NONOate; DPI, diphenyleneiodonium chloride; ESR, electron spin resonance; HO, heme oxygenase; HRP, horseradish peroxidase; L-NAME, L-N ${ }^{\mathrm{G}}$-nitro-arginine methyl ester; mETC, mitochondrial electron transport chain; mtROS, mitochondrial ROS; NADPH, nicotinamide adenine dinucleotide phosphate; NO, nitric oxide; NOS, nitric oxide synthase; NOX, NADPH oxidase; NOX-ROS, NADPH oxidase-derived ROS; PMA, phorbol 12-myristate 13-acetate; RONS, reactive oxygen and nitrogen species; ROS, reactive oxygen species; SnPP, tin protoporphyrin; TC, $S$-methyl-L-thiocitrulline; $\mathrm{ZnPP}$, zinc protoporphyrin.
}

production. Obviously macrophages need to adapt their phenotype in accordance to the environment. Meanwhile it has become evident that the phenotype of macrophages displays a higher plasticity and a more dynamic functional repertoire than previously recognized (23).

Macrophages are particularly challenged under conditions of hemolysis, when they encounter increased levels of hemoglobin or free heme. Endocytosis of haptoglobin-bound hemoglobin via CD163 or uptake of the heme/hemopexin complex (24) lead to increased levels of intracellular heme (25) and initiate hememediated signaling cascades, among others upregulation of $\mathrm{HO}$ $(26,27)$. Recently, it was shown that the treatment of macrophages with hemin (ferric heme) inhibited phagocytosis (28). Currently, it is not clear whether the redox state of the central iron ion of the heme molecule is relevant for the inhibition of phagocytosis and thus for the regulation of macrophage function.

The iron ion in protoporphyrin can exist in a ferrous $\left(\mathrm{Fe}^{2+}\right.$, ferroprotoporphyrin, or heme) or in a ferric form $\left(\mathrm{Fe}^{3+}\right.$, ferriprotoporphyrin, or hemin), which can be further oxidized yielding ferryl species (29). The intracellular reactions mediated by either species are supposed to differ considerably. It is known that at least some heme-dependent processes critically depend on the redox state of heme. Ferrous heme acts as a potent catalyst of the Fenton reaction generating highly active ROS. However, as a regulator of protein function, heme appears to preferentially act in its ferric form within the cell. Ferric heme, and not ferrous heme, was shown to activate RNA-binding protein DGCR8 (30). Function of the heme-containing enzymes, NOS and cytochrome $\mathrm{p} 450$, requires binding of ferric heme (31). It further appears that an enhanced degradation of heme also requires ferric heme, as it mediates proteasomal degradation of the Bach repressor (32), which is required to induce $\mathrm{HO}-1$ transcription. To shed light on the intracellular heme pool, we questioned whether the treatment of J774A.1 cells with ferric heme (hemin) would result in determinable amounts of ferrous heme.

\section{Aims}

The aim of this study is to investigate the contribution of NOS and $\mathrm{HO}$ to the regulation of NOX activity and phagocytosis. Particular attention was paid to the role of mtROS and hemin as modulators of ROS generation and phagocytic activity.

\section{MATERIALS AND METHODS}

\section{Material}

All chemicals used in this study were obtained from SigmaAldrich (St. Louis, MO, USA). HO inhibitors [tin protoporphyrin $(\mathrm{SnPP})$, zinc protoporphyrin $(\mathrm{ZnPP})$, and chromium mesoporphyrin (CrMP)] were obtained from Frontier Scientific (Logan, UT, USA). Fetal calf serum was purchased from Bio \& Sell (Nürnberg, Germany).

\section{Cell Culture}

J774A.1 mouse macrophages (TIB-67 ${ }^{\mathrm{TM}}$; ATCC ${ }^{\circledR}$, Manassas, VA, USA) were grown in Dulbecco's modified Eagle's medium containing high glucose (glucose $25 \mathrm{mM}$, glutamine $4 \mathrm{mM}$, sodium 
bicarbonate $1.5 \mathrm{~g} / \mathrm{l}$, and sodium pyruvate $1 \mathrm{mM}$ ), supplemented with $10 \%$ fetal calf serum. They were grown either adherently in cell culture flasks or in suspension in roller culture. The cells were kept in a humid incubator with $95 \%$ of air and 5\% of carbon dioxide at $37^{\circ} \mathrm{C}$.

\section{Inhibition of Underlying HO Activity of J774A.1 Cells}

The presence of basal $\mathrm{HO}$ activity was confirmed in homogenates of J774A.1 cells using an optimized enzyme-coupled spectrophotometric assay detecting the final product bilirubin (33) (data not shown). Full inhibition of enzyme activity determined in the presence of hemin $(20 \mu \mathrm{M})$ was found for the HO inhibitors $\mathrm{ZnPP}$, SnPP, and CrMP at equimolar concentration $(20 \mu \mathrm{M}$; data not shown). In situ $\mathrm{HO}$ activity was confirmed by the detection of bilirubin in the cell culture supernatant formed from hemin $(20 \mu \mathrm{M})$ after incubation overnight as elsewhere described (33).

\section{Inhibition of NOS Activity}

The basal activity of NOS was confirmed indirectly by the acceleration of mitochondrial $\mathrm{O}_{2}$ consumption rates by NOS inhibitors (data not shown). Effective concentrations of the inhibitors were determined by measuring nitrite $\left(\mathrm{NO}_{2}^{-}\right)$formation from lipopolysaccharide-treated $(1 \mu \mathrm{g} / \mathrm{ml}$ for $16 \mathrm{~h})$ J774A.1 cells. $\mathrm{NO}_{2}^{-}$formation was fully inhibited at concentrations of

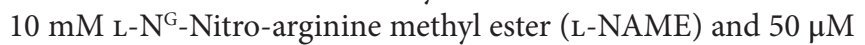
S-methyl-thiocitrulline (TC; data not shown).

\section{Determination of Total ROS, mtROS, and NADPH-Derived ROS (NOX-ROS)}

Reactive oxygen species formation was quantified using Amplex ${ }^{\circledR}$ red (Molecular Probes, Eugene, Oregon, USA). Before the experiment $(24 \mathrm{~h})$, the cells were seeded in low-fluorescence 96-well plates at a density of $6 \times 10^{4}$ cells per well. Experiments were performed in $100 \mu \mathrm{l}$ Krebs buffer [ $\mathrm{NaCl}(135 \mathrm{mM}), \mathrm{KCl}(5 \mathrm{mM})$, $\mathrm{MgSO}_{4}(1 \mathrm{mM}), \mathrm{K}_{2} \mathrm{HPO}_{4}(0.4 \mathrm{mM}), \mathrm{CaCl}_{2}$ (1 mM), HEPES (15 mM), and glucose (25 mM); pH 7.4] containing Amplex ${ }^{\circledR}$ red $(10 \mu \mathrm{M})$, horse radish peroxidase (HRP; $0.2 \mathrm{U} / \mathrm{mL})$, and phorbol 12-myristate 13 -acetate (PMA; $1 \mu \mathrm{M})$. Contribution of mitochondria, NOS, and HO to the determined ROS formation was investigated using mitoTEMPO $(0.5 \mu \mathrm{M})$ or inhibitors of either NOS (L-NAME, $10 \mathrm{mM}$ ) or HO (SnPP, $20 \mu \mathrm{M})$. Each condition was measured in the presence and absence of the NOX inhibitor diphenyleneiodonium chloride (DPI, $0.05 \mu \mathrm{M}$ ). Plates were kept in the dark at $37^{\circ} \mathrm{C}$ for $35 \mathrm{~min}$ measuring fluorescence of the formed resorufin (excitation: $530 \mathrm{~nm}$, emission: $590 \mathrm{~nm}$ ) every $5 \mathrm{~min}$. The fluorescence signals were corrected for background fluorescence determined in wells without cells. The slope of the regression lines calculated from the first $15 \mathrm{~min}$ of resorufin formation was taken as $\mathrm{H}_{2} \mathrm{O}_{2}$ release rate and was displayed as percentage of total $\mathrm{H}_{2} \mathrm{O}_{2}$ release rate in controls. Rates detected in the absence of DPI reflected total $\mathrm{H}_{2} \mathrm{O}_{2}$ production; rates in the presence of DPI were taken as a measure for the mitochondrial $\mathrm{H}_{2} \mathrm{O}_{2}$ production. The difference between total and mitochondrial $\mathrm{H}_{2} \mathrm{O}_{2}$ production was used as a measure for the $\mathrm{H}_{2} \mathrm{O}_{2}$ generation by NOX activity (Figure 1). Modulation of ROS formation

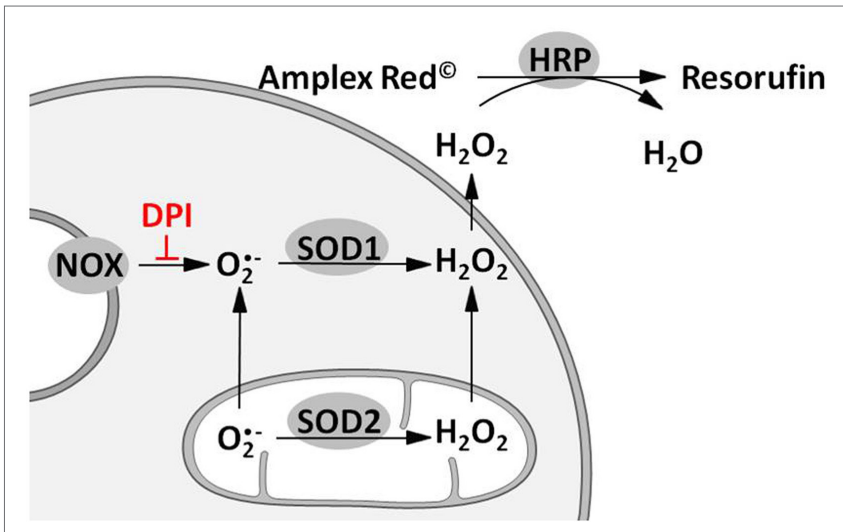

FIGURE 1 | Scheme illustrating the approach for measuring total, mitochondrial $(\mathrm{mt})$ and nicotinamide adenine dinucleotide phosphate oxidase (NOX)-derived reactive oxygen species (ROS) formation. Superoxide radicals formed by either mitochondrial electron transport chain or NOX are converted to hydrogen peroxide $\left(\mathrm{H}_{2} \mathrm{O}_{2}\right)$ by mitochondrial and cytoplasmic superoxide dismutase (SOD1 and SOD2). $\mathrm{H}_{2} \mathrm{O}_{2}$ capable of diffusing through membranes reacts with Amplex ${ }^{\circledR}$ red to resorufin on an equimolar basis in presence of horseradish peroxidase (HRP). Hence fluorescence of resorufin (excitation: 530-560 nm; emission: $590 \mathrm{~nm}$ ) can be used as an indirect measure of ROS formation. Determination of mitochondrial ROS (mtROS) is achieved by inhibition of NOX using diphenyleneiodonium chloride (DPI). Difference of total and mtROS formation reflects NOX-ROS levels.

by mtROS (mitoTEMPO) was determined in $n=5$, by NOS (L-NAME) and HO (SnPP) in $n=3$ independent experiments. Each condition was measured in technical replicates of $n=6$.

\section{Determination of Phagocytosis}

Phagocytic activity was assessed by using Phagotest ${ }^{\mathrm{TM}}$ (Glycotype Bioscience; Berlin, Germany) according to the following protocol. $1 \times 10^{6}$ cells were suspended in $200 \mu$ l Dulbecco's modified Eagle's medium buffered with $25 \mathrm{mM}$ HEPES. The suspension was treated for $60 \mathrm{~min}$ with vehicle (dimethyl sulfoxide) or hemin $(20 \mu \mathrm{M})$ with or without inhibitors of NOS (L-NAME, $10 \mathrm{mM}$; TC, $50 \mu \mathrm{M})$ or HO (ZnPP or CrMP, $20 \mu \mathrm{M})$. The viability of the cells after the initial 60 min of treatment (vehicle, hemin NOS/ HO inhibitors) was analyzed by flow cytometry after propidium iodide staining $(1 \mu \mathrm{g} / \mathrm{ml})$ and was always higher than $90 \%$ (data not shown). Fluorescein isothiocyanate-labeled bacteria $(20 \mu \mathrm{l}$ diluted 1:2) were added, and the suspension was incubated at $37^{\circ} \mathrm{C}$ under shaking. After $30 \mathrm{~min}$, phagocytosis was stopped by placing tubes on ice. Each sample was analyzed in duplicates. In addition, a control sample for each condition was kept on ice to prevent phagocytosis. After adding of $100 \mu$ ice-cold quenching solution and incubation on ice for $3 \mathrm{~min}$, cells were washed with ice-cold wash buffer (phosphate-buffered saline containing $0.3 \%$ fetal calf serum), fixed with $1 \%$ paraformaldehyde for $20 \mathrm{~min}$ at room temperature, washed again, and resuspended in $200 \mu \mathrm{l}$ wash buffer. Uptake of bacteria was assessed on a FACScan (Becton Dickinson, Franklin Lakes, NJ, USA) flow cytometer and analyzed using Cell Quest 3.1 software (Becton Dickinson, Franklin Lakes, NJ, USA). A live gate was set in the scatter plot (forward scatter versus side scatter) to exclude debris. The green fluorescence 
histogram (FL1, 530/30) was analyzed. Autofluorescence of J774A.1 cells was assessed in the respective control samples to set a marker for discrimination between non-phagocytosing and phagocytosing cells. Percentage of gated events above this marker equals the population of phagocytosing cells in the samples. The mean fluorescence in this population was taken as a measure for the number of bacteria taken up per individual cell. For each condition, $n=4$ independent experiments were performed.

\section{Determination of Ferrous Heme by Electron Spin Resonance (ESR) Spectroscopy}

To determine the occurrence of intracellular ferrous heme, we analyzed the spectra of suspension cells treated for $24 \mathrm{~h}$ with vehicle, hemin, or hemin plus diethylenetriamine NONOate (DETA/NO). 5 min before collecting the cells or the supernatants, $1 \mathrm{mM}$ diethylamine NONOate (DEA/NO; $1 \mathrm{mM}$ ) was added to convert all free ferrous heme into the nitrosylated form. The cell suspension was centrifuged $(350 \times \mathrm{g})$, the supernatant was harvested, and the pelleted cells were washed twice with PBS and resuspended in $300 \mu \mathrm{l}$ phosphate-buffered saline. $300 \mu \mathrm{l}$ of the samples were aspirated in standard $1 \mathrm{ml}$ syringes and shock frozen in liquid nitrogen. ESR spectra were recorded at liquid nitrogen temperature $\left(-196^{\circ} \mathrm{C}\right)$ with a Magnettech MiniScope MS 200 ESR spectrometer (Magnettech Ltd., Berlin, Germany). The general settings were as follows: modulation frequency, $100 \mathrm{kHz}$; microwave frequency, $9.425 \mathrm{GHz}$; microwave power, $8.3 \mathrm{~mW}$; modulation amplitude, $5 \mathrm{G}$; gain, 200; range, $330 \pm 20 \mathrm{mT}$. Two independent experiments were performed.

\section{Data Analysis and Statistics}

Data processing and visualization were performed using Excel or GraphPad Prism v6.01 (GraphPad Software Inc., La Jolla, CA, USA). Data are presented as means \pm SEM. Differences between groups were assessed using paired $t$-test for ROS formation and for phagocytosis using matched two-way ANOVA followed by Sidak's multiple comparisons using GraphPad Prism. Differences were considered significant when $p<0.05$.

\section{RESULTS}

\section{Determination of Total ROS, mtROS, and NOX-ROS}

The ROS formation from unstimulated cells was below the detection limit (data not shown). The application of PMA triggered ROS generation (Figure 2A) by activating both mitochondria(Figure 2B) and NOX-dependent (Figure 2C) ROS formation. On treatment with the mitochondria-targeted antioxidant mitoTEMPO, total ROS formation was reduced by $30 \%$ (Figure $\mathbf{2 A}$ ). MitoTEMPO at $0.5 \mu \mathrm{M}$ was sufficient to scavenge about $25 \%$ of mtROS, corresponding to a portion of less than $5 \%$ of total ROS (Figure 2B). This in turn substantially reduced NOX-ROS formation (Figure 2C).

\section{Effect of NOS Inhibition on Formation of mtROS and NOX-ROS}

Inhibition of basal NOS activity reduced ROS formation by $30 \%$

(Figure 3A) in J774.A1 cells. NOS inhibitor attenuated mtROS

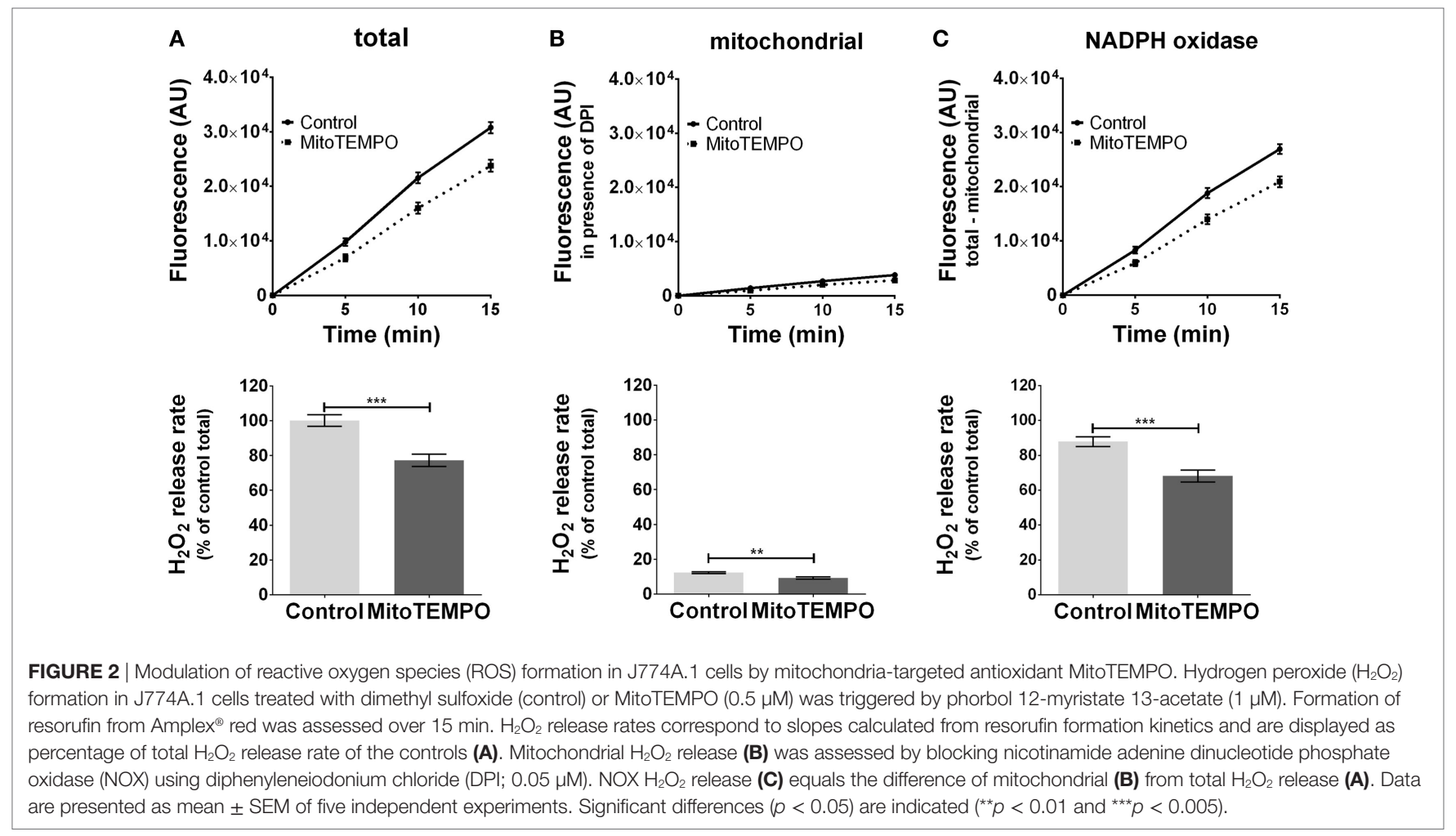


formation (Figure 3B), which was accompanied by decreased ROS formation by NOX (Figure 3C) showing that NOS contributes to an enhanced NOX-ROS generation. These data suggest that $\mathrm{NO}$ activates NOX in a mtROS-dependent manner.

\section{Effect of HO Inhibition on Formation of mtROS and NOX-ROS}

In contrast to inhibitors of NOS, we did not observe a significant effect of $\mathrm{HO}$ inhibitors neither on total ROS (Figure 4A) nor on mtROS (Figure 4B) nor on NOX-ROS (Figure 4C) formation. However, there was a high tendency of an increased mtROS formation from mitochondria $(p=0.0535)$ when $\mathrm{HO}$ was inhibited. Simultaneously the inhibition of HO resulted in a decreased NOX-ROS formation by trend $(p=0.0586)$. Although the determined effects of $\mathrm{HO}$ inhibition were not strong enough to result in significant differences using a replicate number of 3 , we cannot completely exclude a possible contribution of $\mathrm{HO}$ to ROS production. Thus, our data suggest that HO and NOS may affect mitochondrial ROS production in an opposite way.

\section{Effect of NOS Inhibitors on Phagocytosis}

Inhibition of NOS with L-NAME altered neither the percentage of phagocytosing cells (Figure 5A) nor the average number of bacteria ingested per cell (Figure 5B). We confirmed the results using $\mathrm{TC}$, an alternate inhibitor of NOS. Considering that the action of $\mathrm{HO}$ and NOS at the level of phagocytosis can be synergistic, we repeated the experiment in the presence of hemin, the substrate of HO. Hemin strongly impaired phagocytic activity by reducing the number of phagocytosing cells (Figures 5A and 6A) and even more the amount of bacteria ingested per cell (Figures 5B and 6B). But even in the presence of hemin, NOS inhibitors had no effect on the rate of phagocytosis (Figures 5A,B).

\section{Effect of HO Inhibitors on Hemin Modulated Phagocytosis}

Since an inhibition of phagocytosis could be exerted either by hemin or by the products of $\mathrm{HO}$ reaction, we questioned whether the inhibition of basal $\mathrm{HO}$ activity would prevent the observed phagocytosis inhibition. Therefore, we studied phagocytosis in the presence of two different HO inhibitors, ZnPP and CrMP. Both $\mathrm{HO}$ inhibitors per se reduced phagocytosis (Figures 6A,B), especially the number of ingested bacteria per cell (Figure 6B), suggesting that the inhibition of phagocytosis is due to the accumulation of heme. This was confirmed by the further inhibition of phagocytic activity in presence of hemin (Figures 6A,B).

\section{Occurrence of Ferrous Heme within Cells or Cell Supernatant}

Phagocytosis was modulated by changes of $\mathrm{HO}$ activity, which affects the level of the intracellular heme pool. It is possible that the redox state of heme plays a role in this regulation. To understand whether treatment of the cells with ferric heme (hemin) would result in occurrence of intracellular ferrous heme, we additionally treated the cells with the NO-donor DEA/NO, which allows the detection of ferrous heme in its nitrosylated form by low-temperature ESR, due to its unique spectrum. Cells exposed to $1 \mathrm{mM} \mathrm{NO}$-donor DEA/NO for $5 \mathrm{~min}$ did not display any NO-related signal (Figure 7A). Cells treated with hemin for $24 \mathrm{~h}$

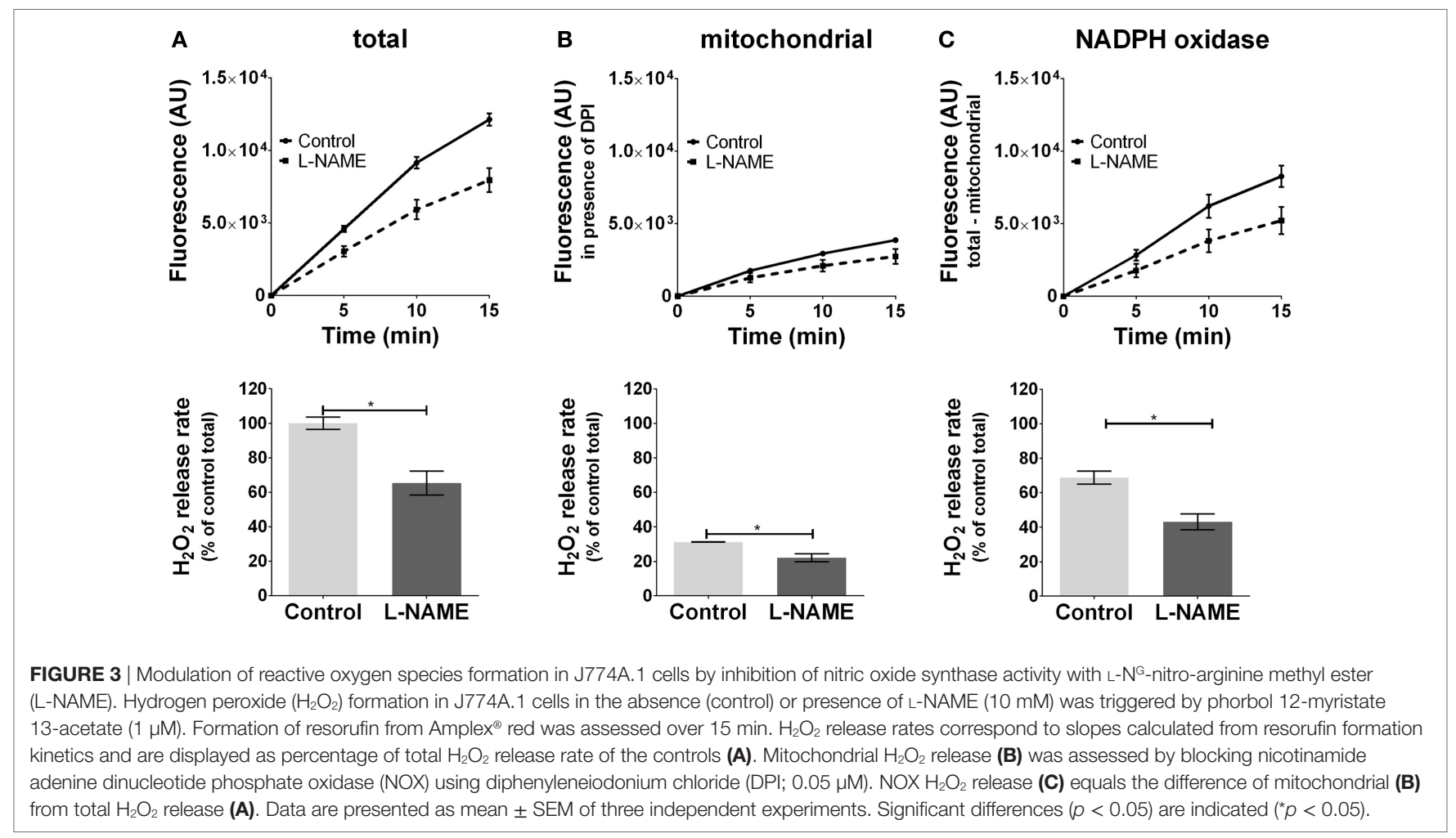



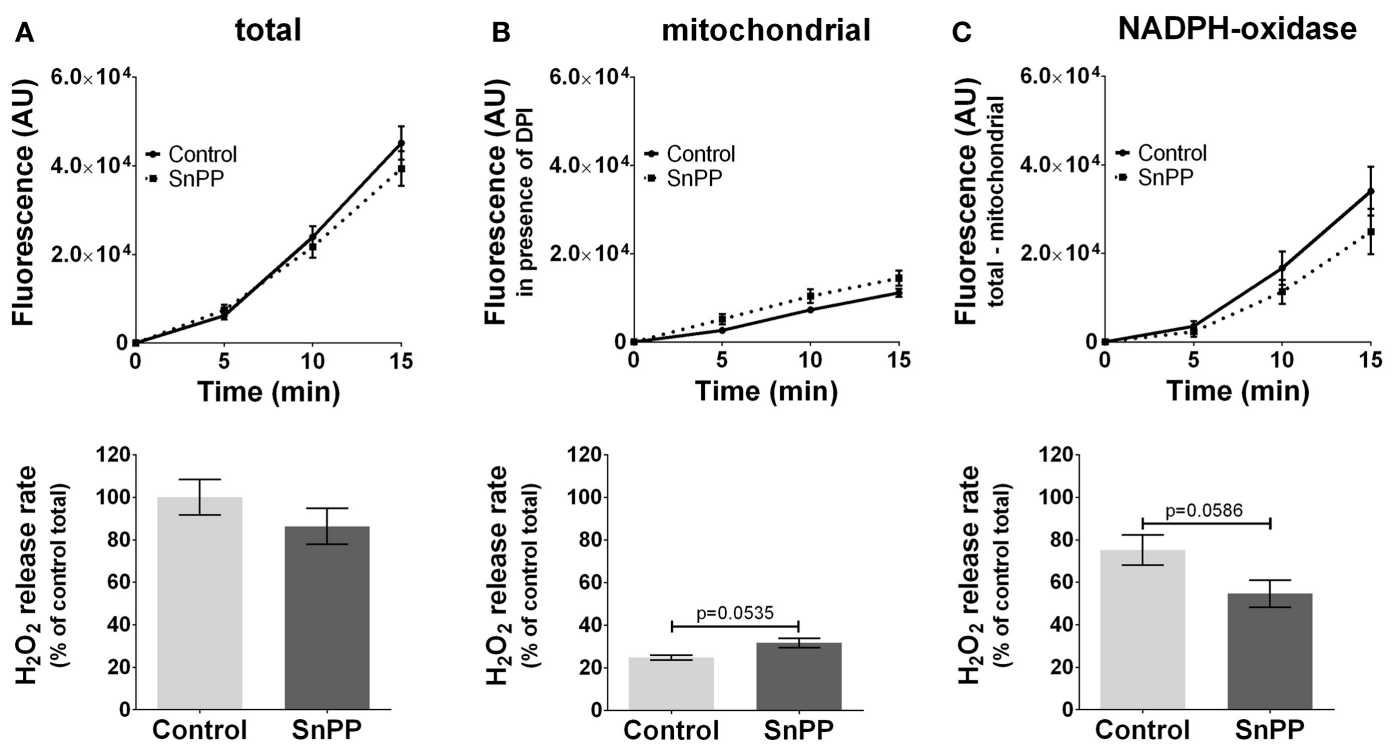

FIGURE 4 | Modulation of reactive oxygen species formation in J774A.1 cells by inhibition of heme oxygenase activity with tin protoporphyrin (SnPP). Hydrogen peroxide $\left(\mathrm{H}_{2} \mathrm{O}_{2}\right)$ formation in J774A.1 cells treated with dimethyl sulfoxide (control) or with SnPP (20 mM) was triggered by phorbol 12 -myristate 13 -acetate $(1 \mu \mathrm{M})$. Formation of resorufin from Amplex ${ }^{\circledR}$ red was assessed over $15 \mathrm{~min} . \mathrm{H}_{2} \mathrm{O}_{2}$ release rates correspond to slopes calculated from resorufin formation kinetics and are displayed as percentage of total $\mathrm{H}_{2} \mathrm{O}_{2}$ release rates of the controls (A). Mitochondrial $\mathrm{H}_{2} \mathrm{O}_{2}$ release (B) was assessed by blocking nicotinamide adenine dinucleotide phosphate oxidase (NOX) using diphenyleneiodonium chloride (DPI; $0.05 \mu \mathrm{M}$ ). $\mathrm{NOX}_{2} \mathrm{O}_{2}$ release (C) equals the difference of mitochondrial (B) from total $\mathrm{H}_{2} \mathrm{O}_{2}$ release $\mathbf{( A )}$. Data are presented as mean \pm SEM of three independent experiments. $p$ values obtained from the statistical analyses are indicated.
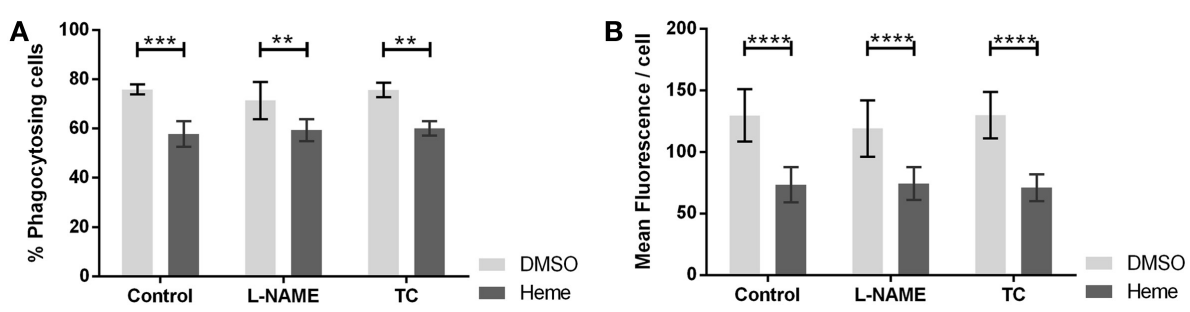

FIGURE 5 | Effect of nitric oxide synthase (NOS) inhibition on phagocytic activity of J774A.1 cells. The amount of phagocytosing cells from the entire population [in $\%(\mathbf{A})$ ] and average amount of phagocytosed bacteria per cell (B) was determined. Macrophages were treated with dimethyl sulfoxide or hemin (20 $\mu \mathrm{M})$ alone (control) or with additional NOS inhibitors L-NG-nitro-arginine methyl ester (L-NAME; $10 \mathrm{mM}$ ) or $S$-methyl-L-thiocitrulline (TC; $50 \mu M$ ). Phagocytic activity was assessed using Phagotest Kit (Glycotype Technology). Data are presented as mean \pm SEM of four independent experiments. Significant differences are indicated as follows $\left({ }^{* *} p<0.01,{ }^{* \star *} p<0.005\right.$, and $\left.{ }^{* \star * *} p<0.001\right)$.
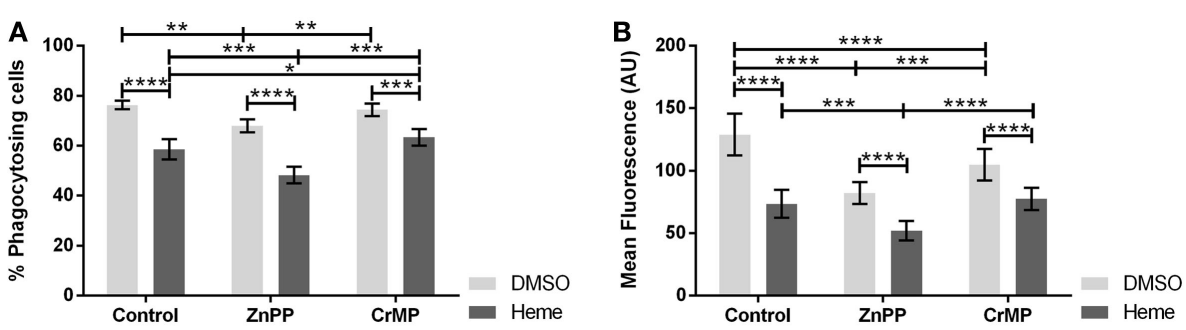

FIGURE 6 | Effect of heme oxygenase $(\mathrm{HO})$ inhibition on phagocytic activity of J774A.1 cells. The amount of phagocytosing cells from the entire population [in \% (A)] and average amount of phagocytosed bacteria per cell (B) was determined. Macrophages were treated with dimethyl sulfoxide (DMSO) or hemin (20 $\mu \mathrm{M})$ alone (control) or with additional $\mathrm{HO}$ inhibitors zinc protoporphyrin (ZnPP; $20 \mu \mathrm{M})$ or chromium mesoporphyrin (CrMP; $20 \mu \mathrm{M})$. Phagocytic activity was assessed using Phagotest Kit (Glycotype Technology). Data are presented as mean \pm SEM of four independent experiments. Significant differences are indicated as follows $\left({ }^{\star} p<0.05,{ }^{\star \star} p<0.01,{ }^{\star \star \star} p<0.005\right.$, and $\left.{ }^{\star \star \star \star *} p<0.001\right)$. 
and exposed to $1 \mathrm{mM} \mathrm{NO}$-donor DEA/NO for the final $5 \mathrm{~min}$ showed the ESR signal typical for NO-heme centered at $g=2.009$ and with the characteristic triplet splitting (Figure 7A). This signal indicates that at least a small portion of intracellular hemeiron occurs in a ferrous form. The signal was strongly increased after the simultaneous treatment with hemin and DETA/NO for $24 \mathrm{~h}$ (Figure 7A) and exposure to $1 \mathrm{mM} \mathrm{NO}$-donor DEA/NO for the final $5 \mathrm{~min}$, suggesting the accumulation of nitrosylated heme inside the cell. None of the supernatants showed a signal arising from nitrosyl-heme complexes. This indicates that exclusively ferric heme is present extracellularly in the supernatants (Figure $7 \mathrm{Ba}-\mathrm{c}$ ) and that the reduction step required to form ferrous from ferric heme, allowing the formation of nitrosyl-heme complexes, occurred inside the cells.

\section{DISCUSSION}

We studied the role of $\mathrm{HO}$ and NOS on ROS generation and phagocytosis, two major tasks of macrophages. NOS and HO play an opposing role in the regulation of macrophages despite the similarity of the biological action of their products $\mathrm{NO}$ and CO. Macrophages with elevated NOS activity are considered to display a pro-inflammatory phenotype, which is associated with the generation of NO and peroxynitrite (20). In contrast, upregulated $\mathrm{HO}$ is associated with a tissue-protective phenotype and a suppressed pro-inflammatory cytokine production. The anti-inflammatory and tissue-protective effects are believed to be mediated mainly by the $\mathrm{HO}$ reaction products, $\mathrm{CO}(34,35)$ and bilirubin (36). In addition, $\mathrm{HO}$ products were shown to inhibit inducible NOS expression and NO formation $(37,38)$. Macrophages activated by pro-inflammatory stimuli produce high levels of NO, by far exceeding the levels of CO that can be reached by active $\mathrm{HO}$. We found that NOS product formation in LPS-stimulated J774A.1 cells was several 100-fold higher than the generation of $\mathrm{HO}$ products upon hemin stimulation within the same time (data not shown). Both $\mathrm{NO}$ and $\mathrm{CO}$ compete with oxygen for the binding to heme proteins of the mETC, such as

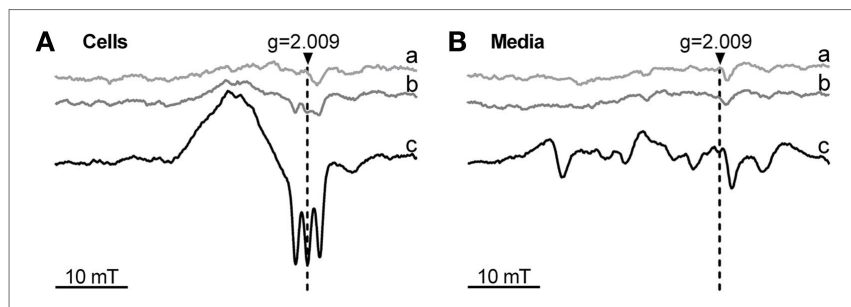

FIGURE 7 | Occurrence of ferrous heme determined by low-temperature electron paramagnetic resonance (ESR) spectra of J774A.1 cells (A) and incubation media (B) after treatment with hemin and nitric oxide (NO) donors. Cells were incubated for $24 \mathrm{~h}$ with medium alone (control; a) or in the presence of hemin $(20 \mu \mathrm{M}$; b) or hemin $(20 \mu \mathrm{M})$ and diethylenetriamine NONOate $(100 \mu \mathrm{M} ; \mathrm{c})$. After incubation, cells were treated with diethylamine NONOate (1 mM) for $5 \mathrm{~min}$. Released nitric oxide and ferrous heme form a nitrosyl-heme complex giving a triplet structured signal centered at $g=2.009$. ESR parameters are described in Section "Materials and Methods." Representative spectra of two independent experiments are shown. g, g-factor; mT, millitesla.
COX. Therefore, the different binding affinities and the concentration ratios of all three ligands to each other determine the overall effects on the mETC. To avoid competition by excessively produced NO, we used macrophages without previous activation (resting macrophages), which display only basal NOS activity. To trigger ROS generation or phagocytosis, we used PMA stimulation or bacterial preparations, respectively.

\section{mtROS Amplify NOX-ROS Formation}

In J774A.1 cells, PMA induced ROS generation from both mitochondria and NOX. This is in line with the former report using human lymphoblasts (39). It was previously shown that mtROS may enhance the activity of NOX (3-5). Since we have found that the amount of ROS generated by mitochondria was about 10 times lower compared to that generated from NOX, we tested whether these levels would be sufficient for an enhancement of NOX activity in J774A1 cells, using the mitochondriatargeted ROS scavenger mitoTEMPO. As expected, mitoTEMPO attenuated mtROS generation, and in addition, it also attenuated generation of NOX-ROS, confirming previous findings in activated macrophages (5). This shows that mtROS contribute to NOX-ROS generation also in resting macrophages. In addition, these data show that mtROS operate as an amplifier of the NOXROS generation and underpin the role of mtROS as an essential regulator of the bactericidal activity of macrophages (5).

Formation of mtROS was shown to be modulated by $\mathrm{NO}$ and CO $(9,40)$. Therefore, both gaseous messengers are possible candidates for an indirect modulation of NOX-ROS generation in macrophages. In addition, it was suggested that NOX as a heme protein may be directly inhibited by $\mathrm{NO}$ or $\mathrm{CO}(41,42)$. In resting macrophages, NOS- and $\mathrm{HO}$-derived $\mathrm{NO}$ and $\mathrm{CO}$ are endogenously produced at low levels. To elucidate the potential of such basal enzyme activity to influence the activity of NOX via formed gaseous messengers, we applied specific NOS and $\mathrm{HO}$ inhibitors.

\section{Basal NOS Contributes to NOX-ROS Formation Via mtROS in Resting Macrophages}

Inhibition of NOS decreased mtROS formation and subsequently NOX-ROS generation. These findings confirm that the ROS-NOS cycle, which was previously described in hepatocytes (7), also exists in macrophages. In addition, the decrease of formation of NOX-ROS by NOS inhibition shows that mtROS formation is modulated by NO, possibly via inhibiting mETC. It should be noted that the macrophages were not activated and that NO production under these conditions is rather low. However, our data suggest that also in resting macrophages basal NOS activity is sufficient to activate NADPH oxidase in a mtROS-dependent manner.

\section{No or Limited Contribution of Basal HO to ROS Formation in Resting Macrophages}

While NOS inhibition affects only NO levels, HO inhibition not only leads to decreased CO levels but also simultaneously to decreased levels of ferrous iron and bilirubin. In addition, 
the inhibition of HO leads to the accumulation of intracellular heme and may thereby promote other heme-mediated reactions as shown by others (43). Therefore, it is not possible to attribute effects in the $\mathrm{HO}$ inhibitor-treated cells solely to the absence of a single HO product. This and the comparably low concentrations of $\mathrm{HO}$ products formed by basal $\mathrm{HO}$ activity might explain that in our model ROS generation was not effected upon inhibition of $\mathrm{HO}$, contrasting previous findings in RAW 264.A cells treated with $\mathrm{HO}$-derived products $(35,36)$. However, there was a trend for a reduction of NOX-ROS generation when HO was inhibited. We found additionally that $\mathrm{HO}$ inhibition increased the mtROS formation by trend, which is in contrast to the findings obtained for the inhibition of NOS. Due to the limited number of replicates $(n=3)$, it is not possible to clearly exclude a modulatory effect of $\mathrm{HO}$ on NOX-ROS and mitochondrial ROS production and a possible contribution of HO on ROS generation in macrophages. Anyway, our data show that $\mathrm{HO}$ and NOS differ considerably regarding their contribution to mitochondrial ROS production. To find out whether these effects are of biological relevance, further studies have to be performed.

\section{NOS Does Not Affect Phagocytosis in Resting J774A.1 Cells}

An efficient phagocytosis is essential for macrophage bactericidal function, besides sufficient ROS formation. In pro-inflammatory macrophages, both NOS $(44)$ and $\mathrm{HO}$ activities $(45,46)$ accelerate the process of phagocytosis. On the other hand, it was shown that knocking out HO-1 results in an increased expression of macrophage-specific scavenger receptor A (47), which is required for phagocytosis and inflammatory signal release (48). Therefore, we questioned whether NOS and $\mathrm{HO}$ activity contribute to the phagocytic activity in resting macrophages as well. NOS inhibitors did neither influence the number of phagocytosing cells nor influence the amount of phagocytosed bacteria. It is known that the substrate of $\mathrm{HO}$, hemin, is an inhibitor of phagocytosis in macrophages (28). Since it is not clear whether NOS or HO products show additional modulating properties, we investigated phagocytosis in cells treated with hemin and simultaneously inhibited $\mathrm{HO}$ and NOS activity.

\section{Hemin Impairs Phagocytosis in Resting J774A.1 Cells}

We observed that hemin reduced phagocytic activity, which is in line with the study performed by Martins et al. (28). Both the number of phagocytosing cells and the amount of bacteria phagocytosed per cell were decreased by hemin treatment, and thus, we questioned whether this effect is mediated by the formation of HO products or by heme itself.

\section{HO Partly Restores Phagocytosis by Degradation of Heme}

Co-treatment of cells with hemin and an $\mathrm{HO}$ inhibitor further decreased the phagocytic activity, suggesting that hemin itself, rather than the $\mathrm{HO}$ products, modulate phagocytic activity. Since active $\mathrm{HO}$ degrades heme, these findings suggest that $\mathrm{HO}$ contributes indirectly to the efficiency of phagocytosis. This is supported by the findings that macrophages and neutrophils from HO-1 knockout animals showed an impaired bacterial clearance upon treatment with heme (28). In addition, we found that treatment with $\mathrm{HO}$ inhibitors alone also reduced phagocytic activity. $\mathrm{HO}$ inhibition is supposed to increase the levels of intracellular heme pool, even in the absence of an external heme supplementation. Thus, our findings indicate that the endogenous basal $\mathrm{HO}$ activity of J774A.1 cells is sufficient to accelerate phagocytosis. Our findings further suggest that it is not the treatment with hemin itself, but the change of the level of the intracellular heme pool, which is responsible for the modulation of phagocytosis.

\section{Heme Exists as Ferrous Heme in the Intracellular Heme Pool}

The reactions catalyzed by heme are dependent on its redox state. The availability of heme in the appropriate redox state appears to play an important role for its regulator function (49). For example, ferric heme, and not ferrous heme, was shown to activate RNA-binding protein DGCR8 (30). It is not known whether (i) the redox state of heme is relevant for the regulation of phagocytosis, (ii) heme within the heme pool exists predominately in its ferrous or ferric form in resting macrophages, and (iii) hemin, the ferric chloride salt of heme, increases the ferrous or ferric heme portion of the intracellular pool in these cells. Due to the reductive environment inside the cell, we expect the intracellular heme pool to contain iron predominantly in its ferrous form. Thus, we expected that treatment with hemin would result in discernable amounts of ferrous heme within J774A.1 cells. Our ESR analyses of heme-treated J774A.1 cells confirmed that a portion of heme exists in its ferrous form, since treatment with NO resulted in a clear nitrosylated heme ESR signal, which was absent in the cell supernatants. However, when cells were treated with NO throughout the incubation period, a stronger signal was determined, indicating an accumulation of the ferrous heme. This suggests that hemin treatment feeds the intracellular heme pool predominately with ferric heme. Our findings further indicate that NO may shift the balance between ferrous and the ferric heme toward the ferrous heme, thereby decreasing the portion of ferric heme. Upregulation of NOS under pro-inflammatory conditions yields higher levels of NO and is therefore supposed to favor the balance toward ferrous heme. Ferric heme, however, is the substrate of $\mathrm{HO}(50)$, which is supposed to predominantly decrease the portion of ferric heme. Thus, it is tempting to speculate that it is the balance between the ferrous and the ferric portion of the heme pool, which determines the predominant phenotype of the macrophage.

We admit as a limitation of our study that modulating effects of the essential enzymes NOS, HO, and NOX were obtained by indirect means, i.e., by using inhibitors of $\mathrm{HO}$ and NOS. Correspondingly, for impairing NOX activity, we used DPI, which is not a selective inhibitor of NADPH oxidases, but an inhibitor of all flavoproteins. For all inhibitors, we have chosen the lowest concentration that is possible to avoid excessive effects. However, further experiments are warranted to confirm our findings, ideally by using complementary methods. 


\section{CONCLUSION}

We showed that both enzymes NOS and HO are essential for important functions of macrophages, namely ROS generation and phagocytosis. While NOS, via its product NO, enhances ROS production, HO indirectly, via decreasing intracellular heme levels, enhances phagocytosis. This indicates that both enzymes contribute to the bactericidal activity of macrophages independently by controlling different pathways.

\section{AUTHOR CONTRIBUTIONS}

$\mathrm{CD}, \mathrm{AK}$, and $\mathrm{AM}$ were responsible for conception and design of the study. AM and GD performed experiments and analyzed

\section{REFERENCES}

1. Fang FC. Antimicrobial reactive oxygen and nitrogen species: concepts and controversies. Nat Rev Microbiol (2004) 2:820-32. doi:10.1038/nrmicro1004

2. Garaude J, cin-Perez R, Martinez-Cano S, Enamorado M, Ugolini M, NistalVillan E, et al. Mitochondrial respiratory-chain adaptations in macrophages contribute to antibacterial host defense. Nat Immunol (2016) 17:1037-45. doi:10.1038/ni.3509

3. Dikalov S. Cross talk between mitochondria and NADPH oxidases. Free Radic Biol Med (2011) 51:1289-301. doi:10.1016/j.freeradbiomed.2011.06.033

4. Daiber A. Redox signaling (cross-talk) from and to mitochondria involves mitochondrial pores and reactive oxygen species. Biochim Biophys Acta (2010) 1797:897-906. doi:10.1016/j.bbabio.2010.01.032

5. West AP, Brodsky IE, Rahner C, Woo DK, Erdjument-Bromage H, Tempst $\mathrm{P}$, et al. TLR signalling augments macrophage bactericidal activity through mitochondrial ROS. Nature (2011) 472:476-80. doi:10.1038/ nature09973

6. Zhou R, Yazdi AS, Menu P, Tschopp J. A role for mitochondria in NLRP3 inflammasome activation. Nature (2011) 469:221-5. doi:10.1038/nature09663

7. Weidinger A, Mullebner A, Paier-Pourani J, Banerjee A, Miller I, Lauterbock L, et al. Vicious inducible nitric oxide synthase-mitochondrial reactive oxygen species cycle accelerates inflammatory response and causes liver injury in rats. Antioxid Redox Signal (2015) 22:572-86. doi:10.1089/ars.2014.5996

8. Lo HM, Chen CL, Yang CM, Wu PH, Tsou CJ, Chiang KW, et al. The carotenoid lutein enhances matrix metalloproteinase- 9 production and phagocytosis through intracellular ROS generation and ERK1/2, p38 MAPK, and RARbeta activation in murine macrophages. J Leukoc Biol (2013) 93:723-35. doi:10.1189/jlb.0512238

9. Kozlov AV, Lancaster JR Jr, Meszaros AT, Weidinger A. Mitochondriameditated pathways of organ failure upon inflammation. Redox Biol (2017) 13:170-81. doi:10.1016/j.redox.2017.05.017

10. Piantadosi CA. Carbon monoxide, reactive oxygen signaling, and oxidative stress. Free Radic Biol Med (2008) 45:562-9. doi:10.1016/j.freeradbiomed. 2008.05.013

11. Tuteja N, Chandra M, Tuteja R, Misra MK. Nitric oxide as a unique bioactive signaling messenger in physiology and pathophysiology. J Biomed Biotechnol (2004) 2004:227-37. doi:10.1155/S1110724304402034

12. Henry Y, Guissani A. Interactions of nitric oxide with hemoproteins: roles of nitric oxide in mitochondria. Cell Mol Life Sci (1999) 55:1003-14. doi:10.1007/ s000180050351

13. Brown GC. Nitric oxide and mitochondrial respiration. Biochim Biophys Acta (1999) 1411:351-69. doi:10.1016/S0005-2728(99)00025-0

14. Schallner N, Romao CC, Biermann J, Lagreze WA, Otterbein LE, Buerkle H, et al. Carbon monoxide abrogates ischemic insult to neuronal cells via the soluble guanylate cyclase-cGMP pathway. PLoS One (2013) 8:e60672. doi:10.1371/journal.pone.0060672

15. Verma A, Hirsch DJ, Glatt CE, Ronnett GV, Snyder SH. Carbon monoxide: a putative neural messenger. Science (1993) 259:381-4. doi:10.1126/science. 7678352 data. $\mathrm{CD}$ and $\mathrm{AK}$ interpreted data and supervised the study. AM, $\mathrm{CD}$, and $\mathrm{AK}$ wrote the manuscript. All authors read and approved the final manuscript.

\section{ACKNOWLEDGMENTS}

We want to thank Stefan Puchner for his excellent technical assistance with performing the ESR analyses.

\section{FUNDING}

AM was supported by the Austrian Research Promotion Agency with a PhD grant: "Industrienahe Dissertation" (849090).

16. Marazioti A, Bucci M, Coletta C, Vellecco V, Baskaran P, Szabo C, et al. Inhibition of nitric oxide-stimulated vasorelaxation by carbon monoxide-releasing molecules. Arterioscler Thromb Vasc Biol (2011) 31:2570-6. doi:10.1161/ATVBAHA.111.229039

17. Zuckerbraun BS, Billiar TR, Otterbein SL, Kim PK, Liu F, Choi AM, et al. Carbon monoxide protects against liver failure through nitric oxideinduced heme oxygenase 1. J Exp Med (2003) 198:1707-16. doi:10.1084/jem. 20031003

18. Taille C, El-Benna J, Lanone S, Boczkowski J, Motterlini R. Mitochondrial respiratory chain and $\mathrm{NAD}(\mathrm{P}) \mathrm{H}$ oxidase are targets for the antiproliferative effect of carbon monoxide in human airway smooth muscle. J Biol Chem (2005) 280:25350-60. doi:10.1074/jbc.M503512200

19. D’Amico G, Lam F, Hagen T, Moncada S. Inhibition of cellular respiration by endogenously produced carbon monoxide. J Cell Sci (2006) 119:2291-8. doi:10.1242/jcs.02914

20. Mustafa AK, Gadalla MM, Snyder SH. Signaling by gasotransmitters. Sci Signal (2009) 2:re2. doi:10.1126/scisignal.268re2

21. Naito Y, Takagi T, Higashimura Y. Heme oxygenase-1 and anti-inflammatory M2 macrophages. Arch Biochem Biophys (2014) 564:83-8. doi:10.1016/j. abb.2014.09.005

22. Schaer CA, Schoedon G, Imhof A, Kurrer MO, Schaer DJ. Constitutive endocytosis of CD163 mediates hemoglobin-heme uptake and determines the noninflammatory and protective transcriptional response of macrophages to hemoglobin. Circ Res (2006) 99:943-50. doi:10.1161/01.RES $0000247067.34173 .1 \mathrm{~b}$

23. Martinez FO, Gordon S. The M1 and M2 paradigm of macrophage activation: time for reassessment. F1000Prime Rep (2014) 6:13. doi:10.12703/P6-13

24. Hvidberg V, Maniecki MB, Jacobsen C, Hojrup P, Moller HJ, Moestrup SK. Identification of the receptor scavenging hemopexin-heme complexes. Blood (2005) 106:2572-9. doi:10.1182/blood-2005-03-1185

25. Khan AA, Quigley JG. Control of intracellular heme levels: heme transporters and heme oxygenases. Biochim Biophys Acta (2011) 1813:668-82. doi:10.1016/j.bbamcr.2011.01.008

26. Abraham NG, Drummond G. CD163-Mediated hemoglobin-heme uptake activates macrophage HO-1, providing an antiinflammatory function. Circ Res (2006) 99:911-4. doi:10.1161/01.RES.0000249616.10603.d6

27. Alam MZ, Devalaraja S, Haldar M. The heme connection: linking erythrocytes and macrophage biology. Front Immunol (2017) 8:33. doi:10.3389/ fimmu.2017.00033

28. Martins R, Maier J, Gorki AD, Huber KV, Sharif O, Starkl P, et al. Heme drives hemolysis-induced susceptibility to infection via disruption of phagocyte functions. Nat Immunol (2016) 17:1361-72. doi:10.1038/ni.3590

29. Kagan VE, Kozlov AV, Tyurina YY, Shvedova AA, Yalowich JC. Antioxidant mechanisms of nitric oxide against iron-catalyzed oxidative stress in cells. Antioxid Redox Signal (2001) 3:189-202. doi:10.1089/152308601300185160

30. Barr I, Smith AT, Chen Y, Senturia R, Burstyn JN, Guo F. Ferric, not ferrous, heme activates RNA-binding protein DGCR8 for primary microRNA processing. Proc Natl Acad Sci U S A (2012) 109:1919-24. doi:10.1073/pnas. 1114514109 
31. Shimizu T. Binding of cysteine thiolate to the Fe(III) heme complex is critical for the function of heme sensor proteins. J Inorg Biochem (2012) 108:171-7. doi:10.1016/j.jinorgbio.2011.08.018

32. Ogawa K, Sun J, Taketani S, Nakajima O, Nishitani C, Sassa S, et al. Heme mediates derepression of Maf recognition element through direct binding to transcription repressor Bach1. EMBO J (2001) 20:2835-43. doi:10.1093/ emboj/20.11.2835

33. Mullebner A, Moldzio R, Redl H, Kozlov AV, Duvigneau JC. Heme degradation by heme oxygenase protects mitochondria but induces ER stress via formed bilirubin. Biomolecules (2015) 5:679-701. doi:10.3390/biom5020679

34. Ryter SW, Otterbein LE. Carbon monoxide in biology and medicine. Bioessays (2004) 26:270-80. doi:10.1002/bies.20005

35. Srisook K, Kim C, Cha YN. Role of NO in enhancing the expression of HO-1 in LPS-stimulated macrophages. Methods Enzymol (2005) 396:368-77. doi:10.1016/S0076-6879(05)96031-X

36. Lanone S, Bloc S, Foresti R, Almolki A, Taille C, Callebert J, et al. Bilirubin decreases nos2 expression via inhibition of $\mathrm{NAD}(\mathrm{P}) \mathrm{H}$ oxidase: implications for protection against endotoxic shock in rats. FASEB J (2005) 19:1890-2. doi:10.1096/fj.04-2368fje

37. Tsoyi K, Ha YM, Kim YM, Lee YS, Kim HJ, Kim HJ, et al. Activation of PPARgamma by carbon monoxide from CORM-2 leads to the inhibition of iNOS but not COX-2 expression in LPS-stimulated macrophages. Inflammation (2009) 32:364-71. doi:10.1007/s10753-009-9144-0

38. Wang WW, Smith DL, Zucker SD. Bilirubin inhibits iNOS expression and NO production in response to endotoxin in rats. Hepatology (2004) 40:424-33. doi:10.1002/hep.20334

39. Dikalov SI, Li W, Doughan AK, Blanco RR, Zafari AM. Mitochondrial reactive oxygen species and calcium uptake regulate activation of phagocytic NADPH oxidase. Am J Physiol Regul Integr Comp Physiol (2012) 302:R1134-42. doi:10.1152/ajpregu.00842.2010

40. Zuckerbraun BS, Chin BY, Bilban M, d'Avila JC, Rao J, Billiar TR, et al. Carbon monoxide signals via inhibition of cytochrome $c$ oxidase and generation of mitochondrial reactive oxygen species. FASEB J (2007) 21:1099-106. doi:10.1096/fj.06-6644com

41. Srisook K, Han SS, Choi HS, Li MH, Ueda H, Kim C, et al. CO from enhanced $\mathrm{HO}$ activity or from CORM-2 inhibits both $\mathrm{O} 2$ - and $\mathrm{NO}$ production and downregulates HO-1 expression in LPS-stimulated macrophages. Biochem Pharmacol (2006) 71:307-18. doi:10.1016/j.bcp.2005.10.042

42. Zollbrecht C, Persson AE, Lundberg JO, Weitzberg E, Carlstrom M. Nitrite-mediated reduction of macrophage NADPH oxidase activity is dependent on xanthine oxidoreductase-derived nitric oxide but independent of S-nitrosation. Redox Biol (2016) 10:119-27. doi:10.1016/j. redox.2016.09.015

43. Dutra FF, Bozza MT. Heme on innate immunity and inflammation. Front Pharmacol (2014) 5:115. doi:10.3389/fphar.2014.00115

44. Tumer C, Bilgin HM, Obay BD, Diken H, Atmaca M, Kelle M. Effect of nitric oxide on phagocytic activity of lipopolysaccharide-induced macrophages: possible role of exogenous L-arginine. Cell Biol Int (2007) 31:565-9. doi:10.1016/j.cellbi.2006.11.029

45. Chiang N, Shinohara M, Dalli J, Mirakaj V, Kibi M, Choi AM, et al. Inhaled carbon monoxide accelerates resolution of inflammation via unique proresolving mediator-heme oxygenase-1 circuits. J Immunol (2013) 190:6378-88. doi:10.4049/jimmunol.1202969

46. Hualin C, Wenli X, Dapeng L, Xijing L, Xiuhua P, Qingfeng P. The anti-inflammatory mechanism of heme oxygenase- 1 induced by hemin in primary rat alveolar macrophages. Inflammation (2012) 35:1087-93. doi:10.1007/ s10753-011-9415-4

47. Orozco LD, Kapturczak MH, Barajas B, Wang X, Weinstein MM, Wong J, et al. Heme oxygenase-1 expression in macrophages plays a beneficial role in atherosclerosis. Circ Res (2007) 100:1703-11. doi:10.1161/CIRCRESAHA. 107.151720

48. Orr GA, Chrisler WB, Cassens KJ, Tan R, Tarasevich BJ, Markillie LM, et al. Cellular recognition and trafficking of amorphous silica nanoparticles by macrophage scavenger receptor A. Nanotoxicology (2011) 5:296-311. doi: $10.3109 / 17435390.2010 .513836$

49. Kuhl T, Imhof D. Regulatory Fe(II/III) heme: the reconstruction of a molecule's biography. Chembiochem (2014) 15:2024-35. doi:10.1002/cbic.201402218

50. Yoshida T, Migita CT. Mechanism of heme degradation by heme oxygenase. J Inorg Biochem (2000) 82:33-41. doi:10.1016/S0162-0134(00)00156-2

Conflict of Interest Statement: The authors declare that the research was conducted in the absence of any commercial or financial relationships that could be construed as a potential conflict of interest.

Copyright (c) 2018 Müllebner, Dorighello, Kozlov and Duvigneau. This is an openaccess article distributed under the terms of the Creative Commons Attribution License (CC BY). The use, distribution or reproduction in other forums is permitted, provided the original author(s) or licensor are credited and that the original publication in this journal is cited, in accordance with accepted academic practice. No use, distribution or reproduction is permitted which does not comply with these terms. 